\title{
NILAI AJARAN INKARNASI DALAM LAKON PURBOSEJATI
}

\author{
I Nyoman Murtana
}

\begin{abstract}
The script of Purbasejati emphasizes the importance of "tapa-brata" (praying and fasting action) or meditation, doing concentration to communicate and harmonize him/herself in God. To reach that level, Javanese people must control their lust as a self sublimation process and increasing soul sensitivity to get miracle and also be able to awakening and manifesting the character of God into them self. The circumstances namely "Manunggaling Kawula lan Gusti", the unity between human being and God, a high value level in Javanese life, such as able to reach a prudent of life and life spirituality. If God is being in theur side, human will get a superiority named sekti and wicaksana. Javanese people believe that in deep inside of wisdom demesnor will shine a fresh pattern of tought and do a highly valued civilization, in order to increase a dignity and prestige of life. In social life context, the wisdome attitude is very useful for society, nation and country.
\end{abstract}

Key words: Inkarnasi,

Pertunjukan wayang sering dikatakan memiliki nilai adiluhung. Nilai ini mungkin dibangun oleh banyak faktor yang terdapat pada seluruh unsur per tunjukan wayang yakni bahasa, rupa, suara, dan gerak sebagai sarana ekspresi. Diduga, bahwa salah satu nilai yang turut membangun keadiluhungan pertunjukan wayang adalah ekspresi religius yaitu ungkapan rasa sujud kepada Tuhan melalui sikap dan prilaku tertentu yang dapat diinderakan melalui ujaran dan tindakan. Nilai ini juga terdapat dalam Lakon Purba Sejati yang melukiskan proses penitisan Rama pada Kresna. Istilah penitisan menimbulkan dugaan, bahwa dalam lakon ini terdapat nilai ajaran inkarnasi. Jika dugaan ini benar, maka nilai-nilai ajaran inkarnasi merupakan salah satu unsur yang turut andil membangun nilai adiluhung.

Di sisi lain nilai adiluhung pertunjukan wayang mulai dipertanyakan aktualitasnya, karena kini tata nilai yang dianut oleh sebagian masyarakat cenderung bergeser menuju nilai-nilai secular. Hal ini menyebabkan nilai keadiluhungan terpojok. Penganutnya yaitu para generasi tua telah kehabisan energi dan kehilangan rasa percaya diri untuk mempertahankan. Nilainilai keagamaan yang terkandung dalam lakon wayang tidak lagi dipahami dan diyakini sebagai landasan filosifi proses berfikir, berujar, dan bertindak, meskipun wayang telah berada pada tataran budaya "adiluhung". Permasa- 
lahannya, bahwa nilai keadiluhungan pertunjukan wayang yang telah melewati proses perumitan (sophisticated process) tidak sepenuhnya dapat memberi kontribusi langsung terhadap sakralitas kehidupan masyarakat masa kini yang modern, berwawasan ke depan, terbuka, maju dan rasional, karena masyarakat tanpa sadar telah melangkah menuju dunia profan. Pemicunya antara lain pola hidup konsumtif yang cenderung menghamba pada dunia materi yang dapat menyeret kehidupan dalam proses sekularisasi.Akibatnya, nilai-nilai seni adiluhung sebagai salah satu wujud kebudayaan ideal terabaikan. Hal ini terkait dengan penemuan dan inovasi kreatif para dalang dalam menyajikan pertunjukan wayang yang dari masa ke masa menunjukkan proses sekularisasi yang antara lain didorong oleh daya "komersial". Ini merupakan salah satu pengaruh inovasi dan penemuan kebudayaan materiil (bandingkan Ogburn dalam Johnson, 1994:112).

Kesenjangan kebudayaan materiil dan kebudayaan non-materiil yang transenden berefek pada sebagian masyarakat pengagum nilai-nilai religiusi tas pertunjukan wayang. Mereka kehilangan pegangan hidup yang dapat memperlemah mentalitas budaya. Bagi yang tidak tahan segera mencari pegangan lain, meskipun kurang memberi dasar keyakinan yang mantap. Keadiluhungan sebagai nilai substantive terkadang masih diupayakan guna mencari tumpuan sesaat, pencerahan sesaat sebagai penghias skeptisisme, sambil melirik berbagai alternatif yang fungsi sosialnya lebih menguntungkan. Akibatnya pertunjukan wayang tidak lagi mampu menegakkan reputasinya sebagai seni adiluhung dan sebagai sumber pencarian nilai-nilai (Amir,1991; Hassan, 1977:42), karena telah terperangkap sebagai seni hibur an. Berbeda dengan situasi pada masa lalu, bahwa dalang selain seorang seniman, juga seorang pendeta atau guru spiritual yang unggul (Mulyono, 1974:76; Covarrubias, 1977:237; Clara van Groenandael, 1987:304). Ini mengindikasikan, bahwa pada saat itu pertunjukan wayang merujuk pada tatanan ideal yang stabil. Masyarakat stabil memiliki pandangan hidup budaya yang dominan berdasarkan kenyataan sosial yang absolut. Berbeda dengan masyarakat pluralistik dimana struktur sosial mudah berubah, berkembang berbagai pandangan hidup, dan pola-pola budaya kompetitif yang sekaligus berarti penyediaan aneka alternatif bagi masyarakat (Johnson, 1994:12). Indikasi ini juga melanda dunia pewayangan (baca: dalang, penonton, patronase).

Naskah Lakon Purba Sejati yang disusun Mujaka Jakaraharja jauh dari suasana vulgar. Ia berisi nilai-nilai adiluhung yang terkait dengan kepercayaan. Selain itu Mujaka Jakaraharja tergolong dalang apik yang serius (Murtiyoso, wawancara tanggal 13 Mei 2005). Lagi pula, situasi pedalangan pada waktu dia masih hidup (dia wafat di panggung saat mendalang pada tahun 1992 di Tawangmangu), belum mengalami disparitas bentuk dan reduksi isi seperti pada era "Pantap dan Reformasi". Ini adalah satu aspek 
yang menggugah peneliti untuk menelaah signifikansi nilai ajaran inkarnasi Lakon Purba Sejati susunannya.

Lakon Purba Sejati adalah sebuah fenomena menarik untuk dikaji. Dilihat dari siklus cerita lakon ini termasuk cerita Mahabarata, tetapi di dalamnya terdapat tokoh-tokoh Ramayana, seperti Sri Rama, Lesmana, Anoman, Jembawan, Trijatha, Rahwana, dan Indrajid (Mursita, 2004:5). Epos Ramayana dan Mahabarata mula-mula terdapat dalam kitab Itihasa Veda sebagai sarana penyebaran ajaran Hindu tentang nilai moral, kewajiban dan tanggung jawab, ketuhanan, cinta kasih, solidaritas sosial, sosial ekonomi, sosial politik, strategi perang dan sebagainya (lihat Kautilya, 2003:10). Menurut Raharjo, Epos Ramayana diciptakan dalam masa Traitayuga, sedangkan Epos Mahabarata diciptakan pada akhir masa Dwaparayuga atau menjelang masa Kaliyuga (Wawancara tanggal 6 Mei 2005). Dilihat dari kesenjangan waktu yang demikian lebar dapat dikatakan, bahwa Lakon Purba Sejati adalah gubahan dalang Jawa yang diduga dikaitkan dengan keyakinan masyarakat Jawa tentang pemujaan roh leluhur. Ini membuktikan adanya kecerdasan pikir (localgenius) yang mencerminkan hasrat, cita-cita, dan kebijaksanaan hidup Jawa. Dalam pertunjukan wayang, menurut Moertono (1985:28), diungkapkan berbagai macam aspek perilaku manusia, mulai dari ketamakan manusia yang paling hina, kelemahan manusia, tipudaya diplomasi, kata-kata jenaka, hingga budi luhur moralitas tinggi, kekuatan keyakinan yang tak dapat disangkal, berlakunya takdir yang tak dapat ditawar, hingga dialog mistik. Semua aspek itu muncul dalam pertunjukan wayang tidak terkecuali dalam Lakon Purba Sejati yang mungkin dicipta untuk upacara Sadranan yang salah satu aspeknya mencerminkan keyakinan dan pemujaan roh leluhur (lihat Hazeu, 1979:94). Seperti diketahui, bahwa lakon Purba Sejati mengisahkan proses inkarnasi roh suci Rama pada Kresna. Dikatakan roh suci, karena Rama sudah meninggal dunia. Ketika hidup, Ra$m a$ adalah ksatria tangguh, budiman, peduli lingkungan, pengayom dunia, dan penegak darma. Inkarnasi ini dilandasi kehendak balas budi Sri Rama pada Lesmana yang pada masa hidup selalu hormat dan setia, maka ketika menitis diberi kesempatan menjadi saudara tua (Naryo Carita, wawancara tgl. 3 Mei 2005; Randyo, wawancara tgl. 25 April 2005).

Rama, putra sulung Dasarata dari Negeri Ayodya, dalam konteks ajaran Hindu diyakini sebagai awatara, yaitu penjelmaan/manifestasi Tuhan di bumi bila terjadi ke-merosotan kebajikan. Ia lahir dari masa ke masa untuk melindungi yang bajik dan me-musnahkan kejahatan demi kebaikan manusia (Sivananda,1993:84; bandingkan Maswinara,1999: 155-62). Awatara dalam perwujudannya merupakan proses inkarnasi atau menitis, yakni hukum alam yang merupakan obyek evolusi alam semesta (S. Pendit, 1994: 49). Dengan kata lain, bahwa penjelmaan atau pengejawantahan Tuhan dalam wujud sebagai Wisnu merupakan kewajiban melaksanakan tugas menjadi pelindung makro dan mikrokosmos agar terhindar dari keserakahan 
dan kebiadaban. Sebagai titisan Wisnu ia menitis pada seseorang untuk dapat melindungi alam semesta ciptaannya agar stabilitas alam dan sosial tetap terpelihara dan segala penghuni dapat menjalani kehidupan sesuai kodrat (lihat Gandasigit dalam Feinstein, dkk.,1986:335-47). Figur yang dianggap paling tepat sebagai wadah berinkarnasi adalah Kresna atau Narayana. Kehidupan Narayana yang dikisahkan dalam Epos Mahabarata, menarik dan unik. Pada masa kanak-kanak, Narayana, putra kedua Basudewa ini nakal dan lincah, tetapi cerdas dan suka melindungi. Secara etimologis hal ini sesuai dengan arti kata Narayana. Nara artinya manusia dan yana, pelindung. Jadi Narayana atau Kresna adalah manusia pelindung, penjelmaan Wisnu (Geertz, 1981:362).

Kajian ini memiliki relevansi untuk menjelaskan kaitan nilai ajaran dan keyakinan inkarnasi dengan budaya survive berdasarkan pengaruh struk tur sosial atau menerangkan struktur sosial berdasarkan sistem nilai dan sistem pengetahuan budaya, serta pembentukan pola pikir dan nilai yang diyakini kelompok sosial berdasarkan perilaku mereka baik dalam bidang sosial, politik, ekonomi, dan budaya (Geertz,1973:143-45; Jazuli, 2004:5).

Selain itu juga berupaya untuk memahami kerangka dan mekanisme berfikir budaya agama dalam dimensi nilai-nilai ajaran inkarnasi dari religiusitas Jawa pra modern yang masih terefleksikan pada sebagian kehidupan masyarakat Jawa masa kini melalui teks Lakon Purba Sejati hasil rekonstruksi dan reproduksi dalang Mujaka Jaka Raharja. Kerangka dan mekanisme berpikir nilai-nilai ajaran inkarnasi di dalam teks lakon itu adalah salah satu proses konstruksi pengetahuan budaya Jawa yang berdimensi religius. Hal ini juga dilatarbelakangi keinginan peneliti untuk melakukan retekstualisasi dan reformulasi (penulisan kembali dan perumusan kembali) kerekatan hubungan antara kerangka dan mekanisme berpikir budaya Jawa dalam teks Lakon Purba Sejati yang fungsi sosialnya bersifat ganda yaitu sebagai tontonan dan tuntunan. Pada masa lalu salah satu fungsi praktis pertunjukan wayang dijadikan ajang penyebaran nilai-nilai ajaran keagamaan. Dalam konteks yang lebih luas dapat disebut sebagai siraman rohani yang menghibur. Nilai-nilai ini terbungkus indah dan rapi dalam berbagai simbol budaya wayang lewat bahasa (prolog, dialog, dan narasi), rupa (figur-figur wayang), suara (gending, sulukan, gerongan, dan sindenan), gerak/sabet (dramatic action). Lingkup sasaran studi ini diarahkan pada interpretasi bidang teks atau naskah lakon dalam bahasa verbal yang berbentuk janturan, pocapan, dan ginem.

Beberapa kajian yang akan dibahas adalah : 1) bagaimana posisi Lakon Purbasejati di antara lakon-lakon lain dalam pertunjukan wayang purwa? 2) bagaimana gambaran proses inkarnasi dalam Lakon Purba Sejati? 3) mengapa Rama memilih berinkarnasi kepada Kresna? 
Analisis terhadap aspek nilai-nilai ajaran penitisan lakon Purba Sejati akan mengungkapkan salah satu pandangan Jawa terhadap wayang, seperti pesan-pesan etika moral dan dimensi religius yang berguna bagi pembangunan watak bangsa. Bagi STSI Surakarta, studi ini adalah salah satu bentuk feedback yang berkait dengan pengelolaan kurikulum dan proses pembelajaran, baik diproyeksikan untuk program penciptaan karya peda-langan maupun karya ilmiah. Dengan demikian terjadi link and match antara pola pikir yang berkembang di masyarakat dengan STSI Surakarta sehingga relevansi perguruan tinggi dapat dipertegas fungsi sosialnya.

Mengingat pertunjukan wayang merupakan penggambaran simbolik kehidupan manusia Jawa yang selalu berinteraksi dengan lingkungan alam, sosial, dan Ke-Tuhan-an, maka analisis simbolik perlu dipertimbangkan.Hal ini agar dapat dijelaskan, dipinjam konsepsi dasar hubungan manusia dengan alam, hubungan manusia dengan sesama, dan hubungan manusia dengan Tuhan yang dalam terminologi Hindu disebut "Tri Hita Karana". Melalui pendekatan dream analysis, analisis simbolik menjadi urgen. Cara kerjanya adalah pemahaman terhadap teks verbal naskah Lakon Purba Sejati yang berbentuk prolog, dialog, dan monolog. Dalam pemahaman Bahasa dan sastera Jawa Herusatoto mengatakan, bahwa Bahasa Jawa yang penuh kembang, lambang dan sinamuning samudana atau tersembunyi dalam kiasan harus dibahas dan dikupas dengan perasaan yang dalam, serta tanggap ing sasmita atau dapat menangkap maksud sebenarnya yang tersembunyi (1991:86). Cara ini menurut Saini KM, memperkuat kehadiran hermeneutika sebagai filsafat atau ilmu tentang metode penafsiran secara ilmiah. Apalagi hidup manusia terus-menerus dituntut menafsirkan gejalagejala, fakta, dan teks yang dapat dilakukan dengan merujuk subjektifitas, pendapat orang lain, dan takhyul, yaitu kepercayaan yang belum dibahas secara kritis (dalam Sumardjo, 2004: vii).

Tujuan substansial kajian ini adalah memberikan gambaran tentang urgensi ajaran inkarnasi bagi kehidupan melalui analisis terhadap proses inkarnasi Rama pada Kresna. Inkarnasi adalah proses penciptaan kembali (proses daur ulang atau reproduksi) terhadap yang sesuatu yang semula dianggap nirguna, usang. Hal ini sekaligus melegitimasi teori penciptaan, bahwa proses penciptaan selalu melibatkan unsur-unsur yang ada. Filsafat Sāńkhya mengatakan, bahwa penciptaan pasti disusun berdasarkan unsurunsur yang ada menjadi bentuk baru yang fungsional bagi kehidupan (Sivananda, 1993:182).

Dalam Lakon Purba Sejati, Rama dikisahkan telah meninggal dunia, tetapi roh ke-Wisnu-annya abadi. Adanya roh memberi indikasi bagi adanya unsur materi. Tuhan memandang, bahwa roh ke-Wisnu-an ini perlu dijelmakan kembali ke dunia untuk "memayu hayuning bawana", karena dibutuhkan untuk menciptakan rasa aman, tenteram, dan sejahtera. Lokus penjelmaanya, yakni Kresna sebagai satu materi yang ada dan siap mene-rima 
inkarnasi. Dalam ajaran inkarnasi, prilaku hidup masa lalu yang terintegrasi dalam terminologi 'karma' menjadi kerangka acuan proses inkarnasi. Karma yang baik diyakini dapat membawa inkarnasi dalam suasana yang semakin baik, dan karma atau perbuatan buruk berinkarnasi pada suasana yang rendah, semakin buruk (Sivananda, 1993:81). Prinsip dasar inkarnasi ini relevan untuk mengkaji inkarnasi Rama pada Kresna, dan sebagai landasan kerja interpretasi diharapkan melahirkan informasi baru.

\section{HAKEKAT LAKON WAHYU PURBA SEJATI}

Menurut Mundardjito, orientasi menunjukan pandangan hidup dan sistem nilai dari masyarakat; persepsi menggambarkan tanggapan masyarakat terhadap dunia luar; sikap hidup mewujudkan tingkah laku masyarakat; dan gaya hidup mewarisi pri kehidupan masyarakat (dalam Ayatrohaedi, 1986:41). Masyarakat Jawa, selain memiliki kepercayaan pada roh keluarga, juga mengenal arwah atau roh yang tidak hanya berasal dari keluarga tertentu. Roh yang dimaksud antara lain adalah Danyang (roh yang menjaga dan mengawasi seluruh masyarakat (desa/dukuh), Baureksa (penjaga tempat seperti sumur tua, pohon beringin tua, dan pada tempat tertentu di hutan (Koentjaraningrat, 1994:338). Pada lokasi yang diyakini ditempati roh-roh biasanya diadakan upacara bersih desa yang disertai dengan menanggap pertunjukan wayang. Lakon Purba Sejati dapat dipentaskan untuk kepentingan ini. Dengan demikian, kehadiran Lakon Purba Sejati dapat dimaknai sebagai ajang penegasan kembali orientasi, persepsi, sikap hidup, dan gaya hidup Jawa.

Masyarakat Jawa khususnya para kawi penyadur karya sastra se-perti Ramayana dan Mahabarata/Baratayuda yang kemudian mengilhami para dalang mengolah karya-karya sastera tersebut untuk dihadirkan kemba-li dalam wujud pertunjukan wayang, ber-hasil menerapkan proses akulturasi dengan menyerap orientasi dan persepsi India untuk memperkuat ketahanan budaya, sikap, dan gaya hidup. Hal ini turut memantapkan jati diri masyarakat Jawa untuk tetap mempertahankan local genius dan mengintegrasikan nilai-nilai atau pola-pola budaya baru ke dalam struktur kehidupan yang ada. Menurut Soerjanto Puspowardojo ini adalah proses pembumian yang mengintegrasikan kebiasaan tradisional untuk menghormat nenek moyang dengan kepercayaan religius yang datang dari India. Tampak bahwa local genius mempunyai kemampuan untuk mengendalikan dan memberikan arah perkembangan kebudayaan. Berdasarkan hal ini, maka M.M. Sukarto K. Atmodjo memberi penegasan mengenai arti dan maksud Local Genius yaitu realisasi dari kemampuan penyerapan secara selektif kebudayaan asing yang kemudian disesuaikan dengan suasana setempat (dalam Ayatrohaedi, 1986: 32\&47). Dari Lakon Wahuyu Purbosejati yang dibawakan oleh beberapa dalang dapat dianalisis sebagai berikut. 
Nilai Ajaran Inkarnasi... (I Nyoman Murtana)

Tabel I

Nama dan Susunan Adegan setiap versi

\begin{tabular}{|c|l|l|l|l|l|}
\hline No & $\begin{array}{l}\text { Mujoka Jaka } \\
\text { Raharjo }\end{array}$ & $\begin{array}{l}\text { Hardjoko Purwo } \\
\text { Pandojo }\end{array}$ & Gondo Warongko & $\begin{array}{c}\text { Ki Naryo } \\
\text { Carito }\end{array}$ & Tata Atmodjo \\
\hline 01 & $\begin{array}{l}\text { Jejer Negara } \\
\text { Dwarawati }\end{array}$ & $\begin{array}{l}\text { Adegan Negara } \\
\text { Dwarawati }\end{array}$ & $\begin{array}{l}\text { Adegan Negara } \\
\text { Dwarawati }\end{array}$ & $\begin{array}{l}\text { Jejer Negara } \\
\text { Dwarawati }\end{array}$ & $\begin{array}{l}\text { Adegan Negara } \\
\text { Dwarawati }\end{array}$ \\
\hline 02 & $\begin{array}{l}\text { Adegan } \\
\text { Tawang- } \\
\text { gantungan }\end{array}$ & $\begin{array}{l}\text { Adegan Tawang- } \\
\text { gantungan }\end{array}$ & $\begin{array}{l}\text { Adegan Negara } \\
\text { Tawang-gantungan }\end{array}$ & $\begin{array}{l}\text { Jejer Negara } \\
\text { Tawanggantung } \\
\text { an }\end{array}$ & $\begin{array}{l}\text { Adegan Negara } \\
\text { Tawang-gantungan }\end{array}$ \\
\hline 03 & $\begin{array}{l}\text { Adegan } \\
\text { Pertapan } \\
\text { Saptaharga }\end{array}$ & $\begin{array}{l}\text { Adegan Pertapan } \\
\text { Saptaharga }\end{array}$ & Adegan tengah Hutan & $\begin{array}{l}\text { Adegan Tengah } \\
\text { Hutan }\end{array}$ & $\begin{array}{l}\text { Adegan Tengah } \\
\text { Hutan }\end{array}$ \\
\hline 04 & $\begin{array}{l}\text { Adegan Negara } \\
\text { Ngamarta }\end{array}$ & $\begin{array}{l}\text { Adegan Kaputren } \\
\text { Negara Dwarawati }\end{array}$ & $\begin{array}{l}\text { Adegan Kahyangan } \\
\text { Suralaya }\end{array}$ & $\begin{array}{l}\text { Adegan } \\
\text { Kahyangan } \\
\text { Suralaya }\end{array}$ & $\begin{array}{l}\text { Adegan Kahyangan } \\
\text { Suralaya }\end{array}$ \\
\hline 05 & $\begin{array}{l}\text { Adegan } \\
\text { Kahyangan } \\
\text { Suralaya }\end{array}$ & $\begin{array}{l}\text { Adegan Kahyangan } \\
\text { Suralaya }\end{array}$ & $\begin{array}{l}\text { Adegan di Tengah } \\
\text { Jalan }\end{array}$ & $\begin{array}{l}\text { Adegan Astana } \\
\text { Gada-madana }\end{array}$ & $\begin{array}{l}\text { Adegan Astana } \\
\text { Gadamadana }\end{array}$ \\
\hline 06 & $\begin{array}{l}\text { Adegan } \\
\text { Pertapan } \\
\text { Kendalisada }\end{array}$ & $\begin{array}{l}\text { Adegan Astana } \\
\text { Gadamana }\end{array}$ & $\begin{array}{l}\text { Adegan Astana } \\
\text { Gadamadana }\end{array}$ & $\begin{array}{l}\text { Adegan Negara } \\
\text { Amarta }\end{array}$ \\
\hline 07 & $\begin{array}{l}\text { Adegan As-tana } \\
\text { Gada-madana }\end{array}$ & $\begin{array}{l}\text { Adegan Negara } \\
\text { Tawang-gantungan }\end{array}$ & & - & $\begin{array}{l}\text { Adegan Kasatriyan } \\
\text { Madukara }\end{array}$ \\
\hline 08 & \multicolumn{1}{|c|}{-} & Adegan Perjalanan. & & $\begin{array}{l}\text { Adegan Gada- } \\
\text { madana }\end{array}$ \\
\hline
\end{tabular}

Tabel II

Rekapitulasi Nama Adegan, Lokus, dan Dalang Pengguna

\begin{tabular}{|l|l|c|l|c|}
\hline N0 & \multicolumn{1}{|c|}{ Nama Adegan } & Lokus & \multicolumn{1}{|c|}{ Dalang Pengguna } & Total \\
\hline 01. & Jejer Negara Dwarawati & I & Mujoko Jokoraharjo, Hardjoko Purwo Pandojo & 2 \\
\hline 02. & Adegan Negara Dwarawati & I & $\begin{array}{l}\text { Gondo Warongko, Naryo Tjarito, dan } \\
\text { Tata Atmodjo }\end{array}$ & 3 \\
\hline 03. & Adegan Tawanggantungan & II & $\begin{array}{l}\text { Mujoko Jokoraharjo, Hardjoko Purwo Pandojo, } \\
\text { Gondo Warongko, Narjo Tjarito, Tata Atmodjo }\end{array}$ & 6 \\
\hline 04. & Adegan Pertapan Saptaharga & III & Mujoko Joko Raharjo Hardjoko Purwo Pandojo & 2 \\
\hline 05. & Adegan tengah Hutan & III & Gondo Warongko, Narjo Tjarito, Tata Atmodjo & 3 \\
\hline 06. & Adegan Negara Ngamarta & IV & Mujoko Jokoraharjo & 2 \\
\hline 07. & $\begin{array}{l}\text { Adegan Kaputren Negara } \\
\text { Dwarawati }\end{array}$ & IV & Hardjoko Purwo Pandojo & 1 \\
\hline 08. & Adegan Kahyangan Suralaya & V (2) & Mujoko Jokoraharjo, Hardjoko Purwo Pandojo \\
& & IV (3) & Gondo Warongko, Narjo Tjarito, Tata Atmodjo & 5 \\
\hline 09. & Adegan di Tengah Jalan & V & Gondo Warongko & 1 \\
\hline 10. & Adegan Astana Gadamana & V (2) & $\begin{array}{l}\text { Mujoko Jokoraharjo, Hardjoko Purwo Pandojo } \\
\text { Gondo Warongko, Narjo Tjarito } \\
\text { Tata Atmodjo }\end{array}$ & 5 \\
\hline 11. & Adegan Pertapan Kendalisada & VI $(2)$ & Mujoko Joko Raharjo & 1 \\
\hline 12. & Adegan Kasatriyan Madukara & VII & Tata Atmodjo & 1 \\
\hline 13. & Adegan Perjalanan & VIII & Hardjoko Purwo Pandojo & 1 \\
\hline 14. & Adegan Gadamadana & VIII & Tata Atmodjo & 1 \\
\hline
\end{tabular}

\section{PERSEPSI MASYARAKAT JAWA TERHADAP LAKON WAHYU}

Perwujudan anugerah dewa yang disebut wahyu ini dapat berupa benda pusaka, senjata, cahaya, figur dewa atau dewi, dan nasehat atau "wejang an" atau "wirid". Semua wahyu dinilai sakral, karena dianugerahkan oleh dewa atau Tuhan. Gambaran isi lakon wahyu seperti ini berpengaruh positif 
terhadap penyajian lakon-lakon jenis wahyu, walau pun wahyu yang diterima oleh tokoh tertentu, selain menguntungkan selalu menjadi pemicu konflik terbuka. Akan tetapi konflik terbuka yang terjadi pada lakon Wahyu Purba Sejati, bukan memperebutkan wahyu itu sendiri, namun karena ulah Dasasukma yang menculik Bratajaya. Masyarakat dan para dalang tidak terpengaruh oleh konflik-konflik yang terjadi pada lakon-lakon wahyu, sehingga mereka dapat menyajikan lakon jenis ini pada hampir semua kesempatan pentas tanpa terikat oleh pelaksanaan hajad tertentu seperti pernikahan, bersih desa, supitan, tingkeban, syukuran, ulang tahun dan sebagainya, karena pada dasarnya masyarakat Jawa selalu berharap memperoleh keselamatan setelah melaksanakan upacara tertentu (Murtiyoso dan Suratno, 1998:58-59). De Jong memberi jawaban dari sisi problematika sosial. Menurutnya, berjuta-juta orang Indonesia hidup dalam ketidakpastian akibat goncangan politik, ekonomi, penjajahan, kemerosotan moril, dan janji palsu. Goncangan ini membuat orang mengembangkan sikap hidup yang bersandar pada bidang mistik (1976:17).Faktor inilah yang mengaitkan pertunjukan wayang lakon-lakon jenis wahyu dengan masyarakat Jawa yang mendorong sikap kreatif para dalang yang cerdas untuk menciptakan lakonlakon wahyu sesuai tuntutan jaman. Secara bentuk dan teknis penyajian tidak serta-merta tampak baru, meskipun mengungkapkan isi yang baru. Hasil kerja inovasi yang dinilai berguna dan secara teknis tidak melompat jauh dari akar-akar budaya tradisi lebih mudah diterima oleh masyarakatnya.Hal ini sesuai dengan pernyataan Simmel yang mengatakan, bahwa kalau seseorang menghasilkan suatu inovasi budaya yang berguna, maka hasil itu akan mudah disatukan dengan dasar budaya yang sudah ada dan dimengerti oleh semua orang (dalam Paul Johnson, 1994:288). Inti dasar pemikiran Simmel ini terefleksi dalam kehidupan pedalangan di Jawa. Jika ada seorang dalang (terutama dalang terkenal dan berbobot) menyajikan lakon baru, maka segera ditiru oleh dalang-dalang lain, sehingga lakon baru itu tersebar, baik pada masyarakat penikmat pewayangan maupun pada para dalang lain. Terkait dengan proses peniruan ini, sejak dulu hingga penelitian ini dilakukan, bukan hal yang penting bagi para dalang untuk mengetahui tentang keberadaan sang inovator yang menggagas dan menghasilkan kebaruan itu, karena masyarakat Jawa tradisional, termasuk para dalang, masih memiliki kecenderungan untuk bersikap komunal. Namun demikian, sikap dan perilaku sosial di era globalisasi yang modern dan cenderung individualistik, ternyata sikap komunalitas sangat mendukung ketahanan budaya wayang dan probabilitas pengembangannya di masa datang, karena setelah suatu karya lahir dapat tersosialisasi dengan cepat dan segera menjadi milik bersama. Pada sisi ini sikap hidup komunalitas menguntungkan.

Dalam Lakon Purba Sejati, tokoh penerima wahyu adalah Arjuna, Kresna, Brata-jaya, dan Baladewa. Mereka menerima wahyu berwujud figur dewa-dewi. Arjuna menerima wahyu penitisan roh Lesmana Sejati, 
Kresna menerima wahyu penitisan roh Rama, Bratajaya menerima wahyu penitisan roh Sinta, dan Baladewa menerima wahyu penitisan dari roh Lesmana Wadat dan roh Basuki. Lakon ini mengingatkan masyarakat Jawa mengenai keselarasan dan keseimbangan tatanan jagat. Kayam mengatakan, bahwa keselarasan dan keseimbangan adalah nilai yang sangat penting bagi orang Jawa, karena dengan keselarasan, harmoni jagat dapat dipertahankan. Konsep harmoni di sini bersifat hirarkhis yang melihat dan menerima tempat kehidupan sebagai suatu jagat yang utuh dan berjenjang-jenjang. Tempat setiap individu telah pasti dan hanya nasib yang mampu menggeser (1989:18). Dalam lakon ini, Dasasukma juga gagal memperistri titisan Widowati seperti Bratajaya. Ketika dia masih hidup juga gagal memperistri Sinta meskipun telah berusaha secara maksimal, mulai dari menculik di hutan Dandaka dan menempatkan Sinta dalam Gedong Batu di Taman Angsoka. Demi mempertahan Sinta, Rahwana mengorbankan rakyat dan Negara Alengka, toh tetap gagal. Kegagalan ini tidak pernah menyebabkannya putus asa.

Kegagalan Dasasukma mengandung pesan, bahwa orang jawa tunduk pada kodrat yang pada hakekatnya pasti, karena diyakini telah dirancang oleh Gusti kang Murbeng Jagat, meskipun dalam realitas manusia secara umum tetap sulit memastikan sesuatu yang akan terjadi. Namun demikian berbagai upaya tetap harus dilakukan demi masa depan yang lebih baik dan secara moral tidak boleh menyerah sebelum berusaha secara maksimal, sekalipun kenyataan yang diterima bersifat paradoks.Inilah nasib yang tidak perlu diratapi, tetapi harus diterima sebagai kodrat dan dikritisi untuk menemukan jalan terbaik bagi kehidupan.

Kepastian kodrati lain juga digambarkan dalam lakon Purba Sejati ini, demikian juga dalam lakon-lakon wahyu yang lain, bahwa wahyu pasti diterima oleh tokoh-tokoh pelaku cerita yang menurut pandangan Jawa adalah figur-figur yang membawa visi dan misi kebaikan yang diharapkan dapat memberi tuah positif bagi kehidupan.Tokoh-tokoh wayang penerima wahyu itu umpamanya salah satu dari keluarga Pandawa yang dalam lakon ini adalah Arjuna yang menerima wahyu berupa roh Lesmana Sejati. Tokoh-tokoh lain yang juga menerima wahyu Purba Sejati adalah Kresna, Baladewa, dan Bratajaya. Sekali wahyu itu diturunkan kepada tokoh-tokoh tertentu, maka tokoh-tokoh lain tidak mampu mengubah, karena sudah bersifat pasti dan diyakini sebagai kodrat. Ini menimbulkan kesan, bahwa Tuhan selalu ditem patkan sebagai Yang Maha Tahu. Beliau tahu sejak awal dan kesudahan tiap-tiap manusia. Sejak awal pula Tuhan telah menentukan siapa yang dipilih dan yang ditolak-Nya. Bagi yang terpilih berusaha sekuat tenaga menjadi unggul dengan melakukan kebaikan dan menolak berbuat jahat (Wiryamartana, 1990:436-37). Sebaliknya Dasasukma tidak menolak berbuat jahat yang menyebabkannya tidak terpilih, sehingga tidak pernah dapat memperistri titisan Wisnu Widowati. Peristiwa ini kembali mempertegas terwujud- 
nya cita-cita masyarakat Jawa yang berusaha merealisasikan konsep equilibrium untuk meletakan tatanan sosial yang selaras dan seimbang. Dalam konteks sosial, individu-individu tidak sangat penting. Mereka melebur diri ke dalam kelompok-kelompok sosial untuk bersama-sama mewujudkan keselarasan dalam masyarakat, karena keselarasan menjamin kehidupan yang baik bagi individu-individu. Setiap orang memiliki tugas dan tanggungjawab moral dan menjaga keselarasan dengan menjalankan kewajiban-kewajiban sosial yang hirarkhis (Kayam,1989:29). Kontrol sosial bersifat langsung, karena orang saling mengenal, saling dapat memeriksa terhadap orang yang melanggar norma (Mulder,1986:36-37).Berdasarkan konsepsi-konsepsi tersebut dapat dikatakan, bahwa kehadiran lakon-lakon wahyu termasuk lakon Wahyu Purba Sejati menjadi penting, karena ditempatkan pada layer (lapisan) bagian dalam dari struktur sosial masyarakat Jawa.

\section{WAHYU PURBA SEJATI (Gambaran Realisasi Ajaran Inkarnasi)}

Dalam pertunjukan wayang banyak dikenal nama-nama dewa, di antaranya Dewa Siwa atau Batara Guru, Indra, Bayu, Wisnu, Yama dan sebagainya. Berbagai keunggulan para dewa menjadi obsesi dan tolok ukur pihak lain yang bukan golongan dewa untuk bersikap dan berprilaku mulia seperti dewa. Para dewa memiliki kebijaksanaan dan manusia mendambakan kebijaksanaan seperti itu, karena ia tidak pernah dapat meraihnya secara penuh (van Peursen,1985:3). Dalam upaya memperoleh sikap bijaksana, manusia melakukan tapa-brata untuk memperhalus budi pekerti, serta mempertinggi harkat dan martabat. Pelaksanaan tapabrata dilandasi dengan kekangan hawa napsu dan jiwa yang dapat ditempuh dengan jalan pengurangan makan, minum, tidur dan berbagai kenikmatan lain yang memabukan. Tindakan pengekangan hawa napsu ini disebut puasa. Puasa dilanjutkan dengan tapa, yaitu memuja Tuhan dalam kurun waktu tertentu dengan tujuan memperoleh anugerah dari Tuhan. Sekilas hal ini tampak sebagai tindakan penyiksaan diri, tetapi sebenarnya adalah suatu upaya untuk memperoleh sublimasi jiwa melalui ritual pembersihan batin dalam rangka menggapai kebahagiaan tertinggi, yaitu dapat bertemu dengan Tuhan. Hal ini dipandang rasional, karena manusia yang dalam keadaan lemah fisik pada saat berpuasa, berusaha sepenuh hati untuk memperoleh kekuatan spiritual dari pihak lain yang diyakini memiliki kekuatan tanpa batas dan pemberi mukjizat tanpa pamrih, yaitu Tuhan. Bila Tuhan Yang Maha Kuasa berpihak, maka yang bersangkutan akan memiliki keunggulan tertentu seperti ketahanan jiwa-raga yang disebut sekti, wicaksana dan sebagainya (Murtana, 2005: 9).

Antara tapa dan semedi memiliki konotasi yang berbeda, meskipun di antara keduanya menerapkan cara yang hampir sama yaitu pengekangan jiwa dan hawa napsu agar sampai pada Hyang Maha Esa. Semedi merupa- 
kan pemusatan pikiran agar jiwa bersatu dengan atman untuk dapat berkomunikasi dengan Hyang Maha Khallik tanpa pamrih yang berkait langsung dengan kebutuhan keduniawian, sedangkan tapa bertujuan untuk memperoleh kebendaan atau aspek tertentu untuk mempermudah kehidupan duniawi. Dilihat dari perbedaan ini, maka istilah yang mungkin lebih dekat untuk menyebut kegiatan menyongsong turunnya wahyu Purba Sejati yang dilakukan oleh Kresna, Bala-dewa, Bratajaya, dan Arjuna adalah tapa-brata, karena wahyu yang diharapkan dapat mereka terima dimaksudkan agar memberi kontribusi langsung terhadap kehidupan duniawi, misalnya demi kelanggengan status sosial, kedudukan atau jabatan, kewibawaan, dan wewenang.

Tokoh-tokoh wayang seperti Rama dan Kresna yang memiliki berbagai keunggulan dipandang sebagai manusia dewa. Oleh karena itu nama kedua tokoh ini ada kalanya didahului dengan kata batara sehingga menjadi Batara Rama dan Batara Kresna. Dalam ajaran Hindu, Rama dan Kresna diyakini sebagai awatara wisnu, juru selamat (Parisada Hindu Dharma, 1978: 34). Para penganutnya memuja Wisnu sebagai Tuhan. Berkaitan dengan ini, mungkin inkarnasi Rama pada Kresna dalam lakon Purba Sejati merupakan indikasi tentang adanya paham Wesnawa yang menyembah wisnu sebagai Tuhan. Pernyataan ini tidak dimaksudkan bagi masyarakat Hindu Jawa, tetapi untuk melihat kisah-kisah dalam Epos Ramayana dan Mahabarata dengan peran Wisnu cukup dominan, baik pada tingkat pengambilan keputusan maupun dalam tindakan yang bersentuhan langsung dengan kehidupan di dunia fana. Melalui peran dan fungsi ini menjadi sinkrun, bahwa Wisnu sebagai manifestasi Tuhan dalam konsepsi Trimurti (Brahma, Wisnu, Siwa) bertugas sebagai pemelihara kehidupan. Tugas ini memungkinkan Wisnu lebih dekat dengan kehidupan di dunia fana, sehingga memudahkan Wisnu memelihara kehidupan. Situasi ini menyebabkan Wisnu dihormati, bahkan dipuja. Sudut pandang ini mungkin berefek terhadap dalang pertama yang menggelar Lakon Purba Sejati. Kemunculannya mungkin bersentuhan mesra dengan pandangan, keyakinan, dan kebutuhan masyarakat, sehingga lakon ini mampu membangun sentimen sosial. Lagi pula berdasarkan catatan sejarah, seni dan agama dikonsepsikan secara jelas dalam Agama Hindu, karena Hindu memasukkan seni dalam persoalan kepercayaan. Seni bagi pemeluk Hindu dikategorikan sebagai prosesi ritual, sekaligus menjadi sarana untuk mempertebal kepercayaan dan filosofi kehidupan (Fananie, 1994:129).

Pengekangan hawa napsu dan jiwa yang dilakukan dengan tekun oleh Kresna, Baladewa, Bratajaya, dan Arjuna, mampu menggetarkan Kahyangan Suralaya. Getaran ini menimbulkan respon atau reaksi, sehingga rapat para dewa yang dipimpin oleh Batara Guru memutuskan Wahyu Purba Sejati diturunkan kepada mereka yang melakukan Semedi atau tapa-brata di Astana Gadamadana. Naradha diberi tugas untuk melakukan hal ini, karena 
ia seorang Resi penghubung antara dua golongan spiritual, yaitu manusia dan para dewata atau makhluk-makhluk yang bercahaya (S. Pendit, 1994: 273).

Secara moril wahyu dianggap berpengaruh positif terhadap peningkatan sikap percaya diri (self confident) penerima wahyu, sehingga penerima wahyu menjadi berwibawa, ampuh atau sekti, memiliki kekuatan untuk mengontrol diri, dan berkemampuan mengatur orang lain dalam jumlah banyak (sekelompok orang, masyarakat, atau rakyat dalam suatu Negara kerajaan. Salah satu dampak materiil, bahwa tokoh penerima wahyu biasanya memiliki kedudukan penting dalam konteks kekuasaan di satu kerajaan dan kaya harta benda. Lazimnya penerima wahyu terbatas pada para Pandawa, keluarga, atau pendukungnya (Murtiyoso dan Suratno,1992:58).Sehubungan dengan itu Subalinata mengatakan, bahwa wahyu hanya bertempat pada orang yang jujur, saleh, murah hati, dan suci. Orang yang seperti ini biasanya raja, calon raja, ksatria atau tokoh yang menurun pada raja (1985:20). Ini berarti tokoh-tokoh penerima wahyu telah memiliki kewibawaan, kekuasaan, dan wewenang. Kewibawaan tidak dapat dipisahkan dari pengertian kekuasaan (power) dan wewenang (authority). Ketiganya saling berkaitan. Kekuasaan merupakan unsur penting dalam suatu masyarakat, baik dalam masyarakat yang susunannya sederhana maupun yang kompleks. Kekuasaan tidak dapat dibagi rata dengan semua orang. Akibatnya timbul makna pokok dari kekuasaan yaitu kemampuan untuk mempengaruhi orang sesuai dengan kehendak pemegang kekuasaan (Soekanto,1973:145). Weber menga takan, bahwa kekuasaan adalah kesempatan dari seseorang atau sekelompok orang untuk menyadarkan masyarakat akan kemauan mereka yang sekaligus menggunakannya untuk melawan orang atau golongan-golongan tertentu (1979:180). Namun kekuasaan bergantung kepada kemampuan pemilik dalam melancarkan pengaruh agar pihak-pihak lain dapat dengan rela atau terpaksa menerima pengaruh.Arjuna,Kresna, Baladewa, dan Bratajaya yang diidolakan menjadi memimpin negara, mampu menciptakan rasa aman, tenteram, adil, dan makmur seperti digambarkan dalam "janturan Jejer" sebagai sebuah deskripsi penting mengenai kemakmuran suatu negara.

Selain itu,tokoh-tokoh tersebut diidolakan oleh masyarakat Jawa seba gai pengemban visi dan misi kebijaksanaan hidup yang mampu beriteraksi secara simultan dengan dimensi ruang dan waktu untuk mencapai keselarasan hubungan manusia dengan Tuhan, keselarasan hubungan manusia dengan alam, dan keselarasan hubungan manusia dengan sesama manusia. Kemampuan untuk melakukan interaksi dengan ketiga hal itu menunjukkan bahwa yang bersangkutan tergolong manusia yang memiliki keunggulan. Oleh karena itu sangat wajar bila menerima wahyu Purba Sejati. 
Nilai Ajaran Inkarnasi... (I Nyoman Murtana)

\section{SIMPULAN}

Lakon Wahyu Purba Sejati yang mengisahkan proses inkarnasi Rama pada Kresna bukan sepenuhnya merupakan inkarnasi yang bersifat dogmatis seperti ajaran dan keyakinan umat Hindu. Penitisan yang diyakini dalam arti dogmatis terjadi dalam proses kelahiran dan yang bersangkutan belum memiliki kesadaran diri kemasukan roh tertentu yang ingin menjelma. Pengertian yang disebutkan terakhir ini berbeda dengan "nitis" dalam lakon Wahyu Purba Sejati yang mendudukan Kresna sebagai figur yang menjadi tempat inkarnasi Rama. Dalam lakon ini Kresna sudah dewasa dan menjadi raja di Dwarawati. Selain itu Kresna sudah memiliki kesadaran dan kepentingan sehubungan dengan akan turunnya wahyu, karena pada hakekatnya wahyu akan turun itu akan dapat melanggengkan kedudukan dan status sosialnya. Oleh karena itu wahyu harus dijemput dengan tindakan ritual tertentu yang dilandasi oleh jiwa yang suci melalui pengekangan hawa napsu dan jiwa. Hal ini dapat ditempuh dengan cara melakukan tapabrata atau semedi dan mengurangi makan, minum, tidur, serta berbagai kesenangan yang memabukan, karena kenikmatan duniawi menyebabkan orang lupa terhadap Tuhan.

Lakon Wahyu Purba Sejati menandaskan pentingnya tapa-semedi (meditation) yang disertai dengan pengekangan hawa napsu dan jiwa untuk memperoleh mukjizat, serta dapat membangkitkan dan menjelmakan sifatsifat ke-Tuhan-an dalam diri manusia (manunggaling kawula lan Gusti). Cara ini diyakini dapat meningkatkan kebijaksanaan dan spirit kehidupan. Dalam jiwa yang bijak terpancar pola pikir dan tindakan beradab, sehingga dapat menjadi salah satu sarana untuk meningkatkan nilai-nilai kehidupan termasuk mewujudkan rasa aman dan tenteram bagi citra kehidupan individu dalam bermasyarakat, berbangsa, dan bernegara. Inilah grand massage yang dikonsepsikan dan ditransmisikan dalam lakon Wahyu Purba Sejati.

\section{DAFTAR RUJUKAN}

Ayatrohaedi (penyunting), 1986. Kepribadian Budaya Bangsa (Local Genius). Jakarta: Pustaka Jaya.

Bizawie, Zainul Milal. 2002. Perlawanan Kultural Agama Rakyat: Pemikiran dan Paham Keagamaan Syekh Ahmad al-Mutamakkin dalam Pergumulan Islam dan Tradisi (1645-1740). Yogyakarta:SAMHA

Clara van Groenendael, Victoria M. 1987. Dalang Di Balik Wayang. Jakarta: PT. Temprint.

Covarrubias, Miguel. 1977. Island Of Bali. Cetakan ke 4. Kuala Lumpur: Oxford University Press.

Fananie, Zainuddin. 1994. Pandangan Dunia KGPAA Hamengkoenagoro I Dalam Babad Tutur: Sebuah Restrukturisasi Budaya. Sukarta: Muhammadyah Unioversity Press Universitas Muhammadiyah Surakarta. 
Nilai Ajaran Inkarnasi... (I Nyoman Murtana)

Feinstein, Alan, dkk. 1986. "Lakon Carangan Jilid II”. Surakarta: Proyek Dokumentasi Lakon Carangan Akademi Seni Karawitan Indonesia (ASKI) Surakarta.

Geertz, Clifford. 1973. Interpretation Of Culture. Selected Essays. New York: Basic Books.

1981. Abangan, Santri, Priyayi Dalam Masyarakat Jawa. Jakarta: Pustaka Jaya . 1992. Tafsir Kebudayaan. Yogyakarta: Kanisius.

Hassan, Fuad. 1977. Heteronomia. Jakarta: Pustaka Jaya.

Hazeu, G.A.J. 1979. Kawruh Asalipun Ringgit Sarta Gegepokanipun Kaliyan Agami ing Jaman Kina. Alih aksara oleh Sumarsana. Terjemahan Hardjana Hp. Jakarta: Departemen Pendidikan Dan Kebudayaan Proyek Penerbitan Buku Bacaan dan Sastra Indonesia dan Daerah.

Herusatoto, Budiono. 1991. Simbolisme dalam Budaya Jawa. Yogyakarta: Hanindita.

Jazuli, M. 2004. Dalang, Negara, Masyarakat: Sosiologi Pedalangan. Semarang: Limpad.

Jong, De. 1976. Salah Satu Sikap Hidup Orang Jawa. Yogyakarta: Penerbitan Yayasan Kanisius.

Kayam, Umar. 1989. Transformasi Budaya Kita. Pidato Pengukuhan Jabatan Guru Besar pada Fakultas Sastra Universitas Gadjah Mada yang Diucapkan di Muka Rapat Senat Terbuka Universitas Gadjah Mada Yogyakarta pada tanggal 19 Mei 1989.

Koentjaraningrat. 1994. Kebudayaan Jawa. Jakarta: Balai Pustaka

Kautilya (Canakya). 2003. Arthasastra. Terjemahan Made Astana dan C.S. Anomdiputra. Surabaya: Paramita.

Maswinara, I Wayan, 1999. Sistem Filsafat Hindu (Sarwa Darsana Samgraha). Surabaya: Paramita.

Moertono, Soemarsaid. 1985. Negara dan Usaha Bina-Negara di Jawa Masa Lampau. Jakarta: Yayasan Obor Indonesia.

Mulder, Niels. 1986. Kepribadian Jawa Dan Pembangunan Nasional. Yogyakarta: Gadjah Mada University Press.

Murtana, I Nyoman. 2005. “Bakti Bima Sorga Pandu”. Surakarta: Jurnal Lakon Vol. 1 No.2. Desember 2004.

Murtiyoso, Bambang, dan Suratno. 1992. "Studi tentang Repertoar Lakon Wayang yang Beredar Lima Tahun Terakhir di Daerah Surakarta," Laporan penelitian pada Masyarakat Musikologi Indonesia (MMI).

Murtiyoso, Bambang, dkk. 1998. "Pertumbuhan dan Perkembangan Seni Pertunjukan Wayang", Laporan penelitian pada STSI Surakarta dan SENA WANGI

Johnson, Doyle Paul. 1994. Teori Sosiologi: Klasik dan Modern.Terjemahan Robert M.Z. Lawang. Jakarta: Gramedia Pustaka Utama.

Parisada Hindu Dharma. 1978. Upadesa Tentang Ajaran Agama Hindu. Kepala Kantor Daerah Direktorat Jenderal Pend. Dasar Dep. P dan K Prop. Bali.

Poloma, Margaret M. 1992. Sosiologi Kontemporer. Cetakan kelima. Jakarta: Raja Grafindi Persada. 
Poespodiprodjo, W. 1987. Interpretasi: Beberapa Catatan Pendekatan Filsafatinya. Bandung: Remadja Karya.

Soekanto, Soerjanto. 1973.Sosiologi Suatu Pengantar. Jakarta: Yayasan Penerbit Universitas Indonesia.

S.Pendit, Nyoman (penterjemah). 1994. Bhagawad-Gita. Jakarta: Anoman Sakti.

Sivananda, Sri Swami. 1993. Intisari Ajaran Hindu. Surabaya: Paramita.

Subalinata, R.S. 1985. Serat Kandhaning Ringgit Purwa Menurut Naskah Tangan 10r 6379. Jilid I. Jakarta: Djambatan dan KITLV

Sumardjo, Jakob. 2004. Hermeneutika Sunda: Simbol-simbol Babad Pakuan/Guru Gantangan. Bandung: Penerbit Kelir.

Van Peursen, C.A. 1985. Orientasi Di Alam Filsafat. Terejemahan Dick Hartoko. Cetakan ke empat. Jakarta: Gramedia.

Weber, Max. 1979. Class, Status, Party. Dalam H.H. Gerth and C. Wright Mills (trans. And eds), Essey in Sociology, New York: Oxford University Press.

Wiryamartana, I Kuntara. 1990. Arjunawiwaha: Transformasi Teks Jawa Kuna Lewat Tanggapan dan Penciptaan di Lingkungan Sastra Jawa. Yogyakarta: Duta Wacana University Press.

\section{Daftar Narasumber}

Murtiyoso, Bambang, 60 tahun, Dosen STSI Surakarta.

Sedyawati, Edy, 67 tahun, Budayawan, Jakarta.

Kuwato, 50 tahun, Dosen Jurusan Pedalangan STSI Surakarta.

Carito, Ki Naryo, 80 tahun, Dalang, Sukoharjo.

Randyo, M., 50 tahun, Dosen Jurusan Pedalangan STSI Surakarta.

Suratno, 52 tahun, Dosen STSI Surakarta.

Suyanto, 45 tahun, Dosen Jurusan Pedalangan STSI Surakarta. 